\title{
EDELBERTO TORRES RIVAS (1930-2018). TRAYECTORIAS DE UNA SOCIOLOGÍA CRÍTICA
}

Héctor Pérez Brignoli

Recibido: 26/09/19 - Aceptado: 02/10/19

Conocí a Edelberto en 1970, en México. La última vez que lo vi fue en San José hace unos pocos años, cuando estaba trabajando sobre la historia de FLACSO en su cincuenta aniversario. Participé en muchos de los proyectos centroamericanos de Edelberto, desde el Programa Centroamericano de Ciencias Sociales del CSUCA, que dirigió entre 1972 y 1976, hasta la Historia General de Centroamérica, que coordinó entre 1989 y 1993. Edelberto tuvo una vida larga y fructífera, dedicada en su mayor parte a la sociología centroamericana, con una meta básica que no varió mucho a lo largo de los años: tratar de entender la dinámica de las sociedades centroamericanas y generar un conocimiento que fuera también útil para construir sociedades mejores, en beneficio de las grandes mayorías postergadas. En este obituario voy a referirme a las trayectorias de su pensamiento sociológico que podemos caracterizar, desde el vamos, como un pensamiento crítico.

Nacido en Guatemala en 1930, vivió como estudiante la primavera democrática de la llamada revolución de octubre de 1944. Después de la caída de Arbenz en 1954, estuvo entre el exilio mexicano, la semiclandestinidad política en Guatemala y sus estudios de derecho. Se graduó en la Universidad de San Carlos en 1962, con una tesis sobre las clases sociales en Guatemala. En 1964 salió hacia Chile para estudiar sociología en la FLACSO, graduándose en 1965. Enseguida trabajó en ILPES y colaboró con Fernando Henrique Cardoso y Enzo Faletto en la investigación que produjo el famoso ensayo sociológico Dependencia y desarrollo en América Latina, publicado como libro en 1969. Edelberto trabajó sobre Centroamérica y publicó un ensayo sobre la región en 1969 con el título: Procesos y estructuras de una sociedad dependiente: El caso de Centroamérica (Santiago de Chile, Prensa Latinoamericana, 1969). Esta obra, revisada y ampliada, dio lugar a la publicación en 1971 de Interpretación del Desarrollo Social Centroamericano (San José, EDUCA, 1971). Este libro puede considerarse como un hito de la 
sociología centroamericana; su esquema teórico cobijó casi todo lo que se produjo en la región en las décadas siguientes.

Los conceptos básicos introducidos en Interpretación del Desarrollo Social Centroamericano fueron, en primer lugar, el de dependencia, siguiendo, obviamente, la línea de Prebisch-Furtado-Cardoso; en segundo lugar, las situaciones de dependencia que ocurrieron en el momento del desarrollo hacia afuera fueron esquematizadas según el control del sector exportador productivo estuviera en manos nacionales o extranjeras; en el caso de Centroamérica eso dio lugar a la tipología: repúblicas cafetaleras-enclaves bananeros. En tercer lugar, Edelberto caracterizó a la estructura del poder y el estado como resultado del poder oligárquico, es decir, un poder basado sobre todo en la gran propiedad agraria, con masas campesinas dependientes y sometidas; un poder y un estado en el cual la democracia electoral y representativa no podía tener más que un desarrollo débil y frecuentemente interrumpido. En la interpretación de Edelberto, la clave para entender las sociedades centroamericanas estaba precisamente en sus estructuras agrarias. En varios trabajos posteriores, y en un esfuerzo orientado sobre todo a entender las particularidades de la evolución costarricense, Edelberto contrastó dos situaciones diferentes: la de predominio de la hacienda oligárquica, típica sobre todo de Guatemala, El Salvador, Honduras y Nicaragua, y la de la vía "farmer", es decir, la predominante en Costa Rica, con pequeños y medianos campesinos propietarios. El enfoque de Interpretación del Desarrollo Social Centroamericano y los trabajos que le siguieron durante las décadas de 1970, 1980 y 1990, estuvo centrado en las estructuras económicas y sociales, con un acento evidente en la estructura y los conflictos de clase. Temas relevantes, pero en esa época poco visibles, como la cuestión étnica, la movilización de los pueblos indígenas y el género, quedaron completamente subsumidos en la estructura de clases.

En los últimos años de su vida Edelberto se interrogó profundamente sobre las revoluciones centroamericanas de la década de 1980 y formuló apreciaciones críticas de gran interés. Su obra más significativa es, en este sentido, Revoluciones sin cambios revolucionarios, publicada en Guatemala en 2011, y reeditada con revisiones en 2013. La tesis central es que las revoluciones en Nicaragua, El Salvador y Guatemala eran inevitables, dada la dinámica brutal del poder oligárquico en esos países y el cierre progresivo de los canales de protesta y disidencia social y política; al mismo tiempo, estas revoluciones resultaron también inviables, dado el contexto internacional y regional, caracterizado por el predominio aplastante del poder de los Estados Unidos y el declive de la Unión Soviética. En este marco, Edelberto estudia los distintos participantes en el conflicto, pero focalizando sobre todo en el actor popular y el estado que enfrentó la insurgencia. El libro se cierra con un capítulo titulado "Las cosechas de la revolución" y un epílogo titulado "El adiós, una nueva época para Centroamérica". A mi modo de ver, toda reflexión crítica sobre la Centroamérica de 
posguerra, sus desafíos y posibilidades, tiene que partir de las ideas planteadas en este libro, concebido como un testimonio combativo y a la vez reflexivo.

Otro aspecto que vale la pena destacar de la larga y fructífera carrera de Edelberto Torres Rivas es su capacidad de gestión de la investigación, consiguiendo fondos y organizando equipos de trabajo para la producción de resultados plasmados en libros, informes y artículos académicos. De sus múltiples proyectos uno de los más exitosos fue la Historia General de Centroamérica, en la que me tocó trabajar como editor de dos de los seis tomos. La obra fue financiada con fondos de la Cooperación española y organizada desde la Secretaría General de la FLACSO entre 1989 y 1993. Como autores de los diferentes capítulos, Edelberto logró reunir a los mejores historiadores especialistas sobre la región, provenientes tanto de la academia norteamericana y europea como de la del área centroamericana; debo señalar que, en este sentido, el proyecto fue un muy exitoso ejemplo de cooperación académica, terminado además a tiempo para la publicación, dentro de las actividades del Quinto Centenario del Descubrimiento.

En suma, Edelberto Torres Rivas fue una figura de primera importancia en el desarrollo de las Ciencias Sociales en Centroamérica. En su larga carrera tuvo, como cualquier persona, éxitos y fracasos, aciertos y equivocaciones; pero lo que no se puede negar es que siempre estuvo movido por un deseo permanente de contribuir a la reflexión crítica y profunda sobre el presente, el pasado y el futuro de las sociedades centroamericanas. Y es esta motivación, además de sus numerosos logros sustantivos, lo que merece nuestro agradecimiento y nuestro permanente reconocimiento.

\section{Bibliografía}

Cardoso, Fernando Henrique y Faletto, Enzo. Dependencia y desarrollo en América Latina. México: Siglo XXI, 1969.

Torres Rivas, Edelberto. Interpretación del desarrollo social centroamericano. San José: EDUCA, 1971.

Torres Rivas, Edelberto. Revoluciones sin cambios revolucionarios. Ensayos sobre la crisis en Centroamérica. Guatemala: F\&G Editores.

Torres Rivas, Edelberto. (Ed.). Historia general de Centroamérica. Madrid: Ediciones Siruela, 1993. Torres Rivas, Edelberto. (Ed.). Historia general de Centroamérica. San José: FLACSO, 1994.

Héctor Pérez Brignoli. Costarricense, Doctorado de tercer ciclo en Historia por la Universidad de París, 1975. Profesor emérito de la Universidad de Costa Rica y de la Universidad Nacional. Programa Centroamericano de Población, Centro de Investigaciones Históricas de América Central, Universidad de Costa Rica.

Contacto: hector.perez@ucr.ac.cr

ORCID: 0000-0001-7038-8301 